\title{
Constructal dendritic configuration for the radiation heating of a solid stream
}

\author{
Deok-Hong Kang, ${ }^{1}$ Sylvie Lorente ${ }^{2}$ and Adrian Bejan ${ }^{3, a)}$ \\ ${ }^{1}$ Department of Energy and Resources Research, Research Institute of Industrial Science and Technology, \\ Pohang 790-600, South Korea \\ ${ }^{2}$ UPS, INSA; LMDC (Laboratoire Materiaux et Durabilité des Constructions), Université de Toulouse, \\ 135 avenue de Rangueil, F-31 077 Toulouse Cedex 04, France \\ ${ }^{3}$ Department of Mechanical Engineering and Material Science, Duke University, Durham, \\ North Carolina 27708-0300, USA
}

(Received 12 March 2010; accepted 21 April 2010; published online 14 June 2010)

\begin{abstract}
Here we show that the configuration of a slender enclosure can be optimized such that the radiation heating of a stream of solid is performed with minimal fuel consumption at the global level. The solid moves longitudinally at constant rate through the enclosure. The enclosure is heated by gas burners distributed arbitrarily, in a manner that is to be determined. The total contact area for heat transfer between the hot enclosure and the cold solid is fixed. We find that minimal global fuel consumption is achieved when the longitudinal distribution of heaters is nonuniform, with more heaters near the exit than the entrance. The reduction in fuel consumption relative to when the heaters are distributed uniformly is of order $10 \%$. Tapering the plan view (the floor) of the heating area yields an additional reduction in overall fuel consumption. The best shape is when the floor area is a slender triangle on which the cold solid enters by crossing the base. These architectural features recommend the proposal to organize the flow of the solid as a dendritic design, which enters as several branches, and exits as a single hot stream of prescribed temperature. The thermodynamics of heating is presented in modern terms in the Sec. VII (exergy destruction, entropy generation). The contribution is that to optimize "thermodynamically" is the same as reducing the consumption of fuel. (C) 2010 American Institute of Physics. [doi:10.1063/1.3429195]
\end{abstract}

\section{INTRODUCTION}

In this paper we consider the fundamentals of heating a stream of solid by radiation in a very slender enclosure through which the solid moves longitudinally. We consider the question of whether the shape of the enclosure can be selected such that the total rate of fuel consumption in the enclosure is minimal. This approach is an application of the method of design with the constructal law, ${ }^{1,2}$ according to which the search is for the architecture of the freely morphing flow system, in the pursuit of greater performance at the global level.

The reduction in fuel consumption in industrial furnaces is key to being able to control the rise of $\mathrm{CO}_{2}$ emissions at the national and global level. In South Korea, for example, the furnace industry constitutes a $17 \%$ share of the amount of fuel consumed in all the industries. This represents $9.6 \%$ of the national energy consumption. In 2005, the $\mathrm{CO}_{2}$ emissions related to fuel use amounted to 60 million ton $\mathrm{CO}_{2} / \mathrm{yr}$. In view of this, the government of South Korea has initiated a policy of "Green Energy Industry as a Growth Engine," in which the reduction in fuel use is a major objective.

To reduce the consumption of fuel in a furnace is practically the same as optimizing the furnace thermodynamically, i.e., the same as reducing the entropy generation rate in the furnace. We will demonstrate this equivalence in Sec.

\footnotetext{
a) Author to whom correspondence should be addressed. Electronic mail: abejan@duke.edu.
}

VII. The analysis and results presented in the paper are based on minimizing the total rate of fuel consumption.

In this paper we treat the subject fundamentally, and arrive at the unexpected conclusion that the layout of furnaces in the future should be tapered, such that the flow of solid on their floor area should be tree-shaped. The tree architecture coincides with other tree designs that occur in nature and engineering, however, its emergence here, in this heating process, is totally unexpected.

\section{MODEL}

The research literature on furnace design and optimization is concerned mainly with the optimal control to improve energy consumption and to meet quality requirements for the slab heating process of a reheating furnace in a hot strip mill. ${ }^{3-13}$ Full numerical simulations of heat transfer and fluid flow in reheating furnaces are also being reported. ${ }^{14-21}$ The feature that these studies have in common is that each study focuses on a specified configuration of reheating furnace and combustion.

In the model used in this study, the configuration is not specified. The configuration is the unknown. The furnace consists of a stream of moving steel slabs of mass flow rate, $\mathrm{m}_{\mathrm{s}}[\mathrm{kg} / \mathrm{s}]$, which are exposed to heating all along the length of the enclosure, L. The enclosure is very slender. The steel enters at $\mathrm{x}=\mathrm{L}$ and exits at $\mathrm{x}=0$.

The heating is provided by a large number of gas burners distributed arbitrarily along the furnace. We model this dis- 

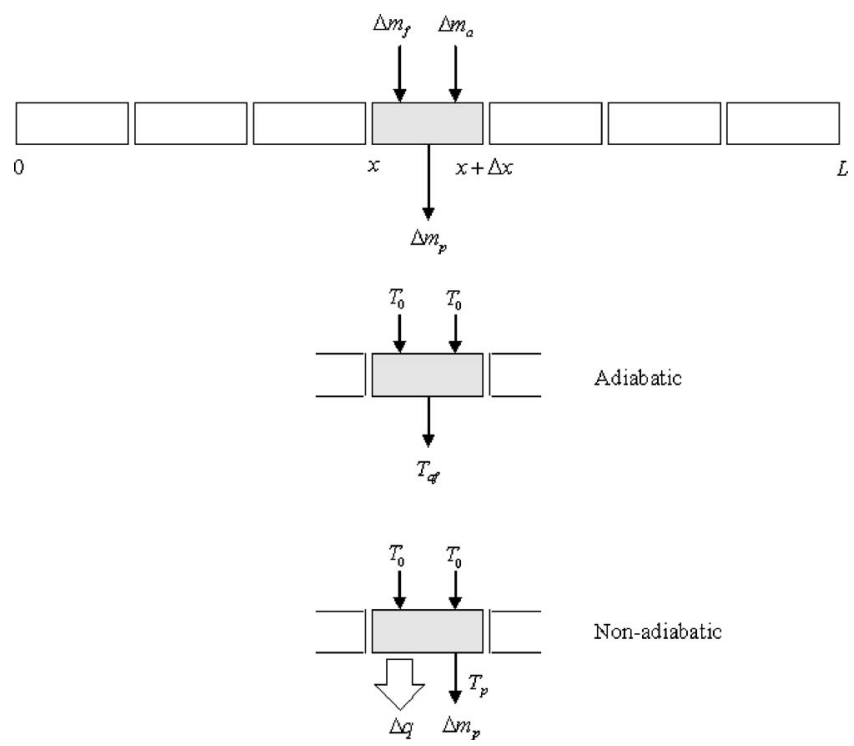

FIG. 1. Model of a large number of gas heaters distributed along the furnace.

tribution as a string of infinitesimal burners of length $\Delta x$, as shown in Fig. 1. The $\Delta \mathrm{x}$ burner receives $\Delta \mathrm{m}_{\mathrm{f}}[\mathrm{kg} / \mathrm{s}]$ of fuel and $\Delta \mathrm{m}_{\mathrm{a}}[\mathrm{kg} / \mathrm{s}]$ of oxidant such as air, and discharges $\Delta \mathrm{m}_{\mathrm{p}}[\mathrm{kg} / \mathrm{s}]$ of gaseous products of combustion. Mass conservation $\left(\Delta \mathrm{m}_{\mathrm{f}}+\Delta \mathrm{m}_{\mathrm{a}}=\Delta \mathrm{m}_{\mathrm{p}}\right)$ and stoichiometry $\left(\Delta \mathrm{m}_{\mathrm{a}} / \Delta \mathrm{m}_{\mathrm{f}}\right.$ =constant) indicate that $\Delta \mathrm{m}_{\mathrm{p}}$ is proportional to $\Delta \mathrm{m}_{\mathrm{f}}$, and can be used as a measure of the rate of fuel that is being burned. In other words, the ratio $\Delta \mathrm{m}_{\mathrm{p}} / \Delta \mathrm{m}_{\mathrm{f}}$ is a known constant. To minimize the total rate of fuel consumption is the same as minimizing the total stream of gaseous products issuing from the furnace. The thermodynamic optimization of the process is discussed in greater detail in Sec. VII.

The fuel and oxidant enter the $\Delta \mathrm{x}$ burner at ambient conditions $\left(\mathrm{T}_{0}, \mathrm{P}_{0}\right)$. The pressure changes in the combustion chamber are negligible. If the chamber functions adiabatically, then the products exit at the adiabatic flame temperature $\mathrm{T}_{\mathrm{af}}$, which is a constant known for each combination of fuel and oxidant. ${ }^{21}$ The limit of adiabatic operation is sketched in the middle part of Fig. 1.

The actual combustor is not adiabatic. It generates the heat transfer rate $\Delta \mathrm{q}$ and, as a consequence, the stream $\Delta \mathrm{m}_{\mathrm{p}}$ is at a temperature $\left(\mathrm{T}_{\mathrm{p}}\right)$ lower than $\mathrm{T}_{\mathrm{af}}$. This situation is sketched in the lower part of Fig. 1. The conservation of energy requires (Ref. 22, p. 101)

$$
\Delta \mathrm{q}=\Delta \mathrm{m}_{\mathrm{p}} \mathrm{c}_{\mathrm{p}}\left(\mathrm{T}_{\mathrm{af}}-\mathrm{T}_{\mathrm{p}}\right) \text {, }
$$

where the $c_{p}$ is the specific heat at constant pressure of the products. Here we make the approximation that $\mathrm{T}_{\mathrm{af}}$ is considerably greater than $T_{p}$, such that $\left(T_{a f}-T_{p}\right)$ may be regarded as relatively constant. This leads to the conclusion that the heat released $\Delta q$ is proportional to the fuel consumption rate (or gas generation rate $\Delta \mathrm{m}_{\mathrm{p}}$ ), which can be written per unit length as

$$
\mathrm{q}^{\prime}(\mathrm{x})=\mathrm{am}_{\mathrm{p}}^{\prime} \text {. }
$$

This equation comes from writing $\mathrm{q}^{\prime}=\Delta \mathrm{q} / \Delta \mathrm{x}$ and $\mathrm{m}_{\mathrm{p}}^{\prime}$ $=\Delta \mathrm{m}_{\mathrm{p}} / \Delta \mathrm{x}$, where $\mathrm{a}$ is a proportionality factor proportional to the heating value of the fuel $\mathrm{HV}$, which means the amount of heat released by combusting a specific amount of gas fuel, in other words

$$
\mathrm{m}_{\text {fuel }} \mathrm{HV}=\mathrm{am}_{\mathrm{p}},
$$

where the ratio $\mathrm{m}_{\mathrm{p}} / \mathrm{m}_{\text {fuel }}$ is dictated by stoichiometry. In current industrial furnace design, $\mathrm{m}_{\mathrm{p}} / \mathrm{m}_{\text {fuel }}$ is of order $6, \mathrm{HV}$ $=1.67 \times 10^{7} \mathrm{~J} / \mathrm{kg}$, and consequently, $\mathrm{a}=2.75 \times 10^{6} \mathrm{~J} / \mathrm{kg}$, all in an order of magnitude sense.

The steel is a steady stream of temperature $T_{s}(x)$ and mass flow rate $\mathrm{m}_{\mathrm{s}}[\mathrm{kg} / \mathrm{s}]$, entering at $\mathrm{T}_{\mathrm{s}}=\mathrm{T}_{0}$ at $\mathrm{x}=\mathrm{L}$, and exiting at $\mathrm{T}_{\mathrm{S}}=\mathrm{T}_{\text {out }}$ at $\mathrm{x}=0$. The end temperatures are fixed: $\mathrm{T}_{0}$ is the ambient temperature and $\mathrm{T}_{\text {out }}$ is the design (target) temperature of the steel heating process.

The steel runs in counterflow with the stream of hot gases of combustion, $\mathrm{m}_{\mathrm{p}}(\mathrm{x})$. The spatial distribution of combustion $\left[\mathrm{m}_{\mathrm{p}}^{\prime}(\mathrm{x})\right]$ is the chief degree of freedom of the design, however, if $\mathrm{m}_{\mathrm{p}}^{\prime}$ is known then the mass flow rate of the gas stream can be calculated,

$$
\mathrm{m}_{\mathrm{p}}(\mathrm{x})=\mathrm{m}_{\mathrm{p}}(0)+\int_{0}^{\mathrm{L}} \mathrm{m}_{\mathrm{p}}^{\prime} \mathrm{dx}
$$

The gas temperature is $T_{p}(x)$. For simplicity in this treatment of the distributed heating configuration, we neglect convection and assume that the gas-steel heat transfer is dominated by radiation. The local heat transfer rate from wall to steel is

$$
\mathrm{q}_{\mathrm{i}}^{\prime}=\sigma \mathrm{F}^{\prime} \mathrm{p}(\mathrm{x})\left(\mathrm{T}_{\mathrm{p}}^{4}-\mathrm{T}_{\mathrm{s}}^{4}\right) .
$$

The factor $\mathrm{F}^{\prime}$ is shorthand for $\left(\varepsilon_{\mathrm{p}}^{-1}+\varepsilon_{\mathrm{s}}^{-1}-1\right)^{-1}$, where $\varepsilon_{\mathrm{s}}$ and $\varepsilon_{\mathrm{p}}$ are the total hemispherical emissivities of the steel surface and the enclosure surfaces, at temperatures $T_{s}$ and $T_{p}$, respectively. We expect $\varepsilon_{\mathrm{s}}$ and $\varepsilon_{\mathrm{p}}$ to be of order 1, and this means that $\mathrm{F}^{\prime}$ is a constant factor of order 1 .

The heat transfer area per unit of furnace length $\mathrm{p}(\mathrm{x})$ is another degree of freedom of the design. The total heat transfer area is fixed,

$$
\int_{0}^{\mathrm{L}} \mathrm{pdx}=\mathrm{A} .
$$

If the cross-section of the furnace is flat (like a slit), and if the height of the ceiling is uniform, then $\mathrm{p}(\mathrm{x})$ is a function that varies in the same way as the shape of the floor. This is why in the following discussion the designs with $p$ $=$ constant and $\mathrm{p} / \mathrm{x}=$ constant are described as floors with constant-width and triangular (tapered) floors, respectively.

According to the upper part of Fig. 2, the first law of thermodynamics for the furnace element of length $\mathrm{dx}$ requires

$$
\begin{aligned}
\mathrm{am}_{\mathrm{p}}^{\prime}= & \mathrm{c}_{\mathrm{p}}\left(\mathrm{T}_{\mathrm{p}}-\mathrm{T}_{0}\right) \mathrm{m}_{\mathrm{p}}^{\prime}-\mathrm{m}_{\mathrm{s}} \mathrm{c}_{\mathrm{s}} \frac{\mathrm{d}\left(\mathrm{T}_{\mathrm{s}}-\mathrm{T}_{0}\right)}{\mathrm{dx}} \\
& +\mathrm{m}_{\mathrm{p}} \mathrm{c}_{\mathrm{p}} \frac{\mathrm{d}\left(\mathrm{T}_{\mathrm{p}}-\mathrm{T}_{0}\right)}{\mathrm{dx}}
\end{aligned}
$$

Written for the steel stream alone (Fig. 2, bottom), the first law requires

$$
\sigma \mathrm{F}^{\prime} \mathrm{p}(\mathrm{x})\left(\mathrm{T}_{\mathrm{p}}^{4}-\mathrm{T}_{\mathrm{s}}^{4}\right) \mathrm{dx}=-\mathrm{m}_{\mathrm{s}} \mathrm{c}_{\mathrm{s}} \mathrm{d}\left(\mathrm{T}_{\mathrm{s}}-\mathrm{T}_{0}\right) .
$$




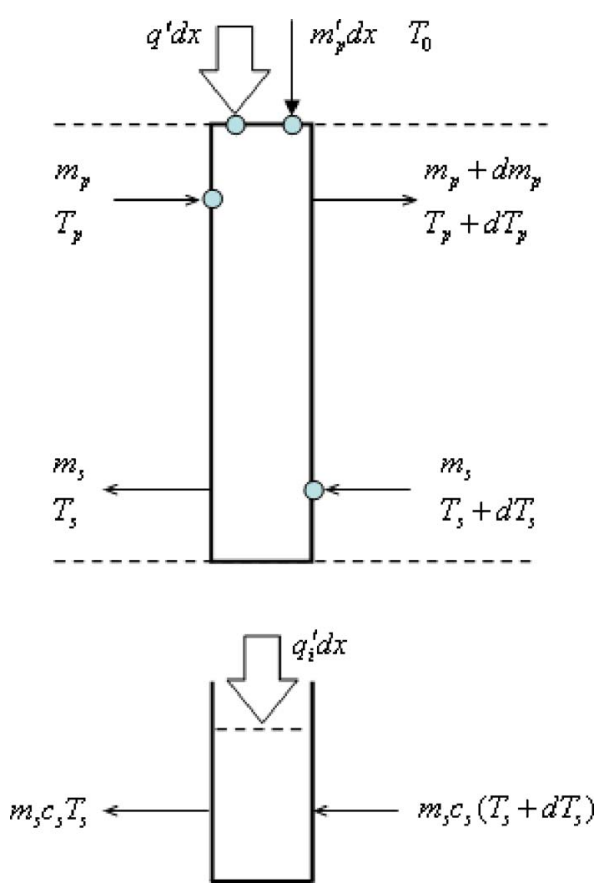

FIG. 2. (Color online) The streams of hot gas, steel, and energy for an elemental length of the furnace.

The scale analysis of Eqs. (2)-(8) reveals the scales

$$
\begin{aligned}
& \mathrm{p}_{\text {scale }}=\frac{\mathrm{A}}{\mathrm{L}}, \quad \mathrm{x}_{\text {scale }}=\mathrm{L}, \quad \mathrm{m}_{\text {scale }}=\frac{\sigma \mathrm{F}^{\prime} \mathrm{A} \Delta \mathrm{T}^{3}}{\mathrm{c}_{\mathrm{s}}}, \\
& \left(\mathrm{T}-\mathrm{T}_{0}\right)_{\text {scale }}=\mathrm{T}_{\text {out }}-\mathrm{T}_{0}=\Delta \mathrm{T},
\end{aligned}
$$

which recommend the dimensionless variables

$$
\tilde{\mathrm{p}}=\frac{\mathrm{p}}{\mathrm{A} / \mathrm{L}}, \quad \xi=\frac{\mathrm{x}}{\mathrm{L}}, \quad \widetilde{\mathrm{T}}=\frac{\mathrm{T}-\mathrm{T}_{0}}{\Delta \mathrm{T}}, \quad \tilde{\mathrm{m}}=\frac{\mathrm{m}}{\mathrm{m}_{\text {scale }}} .
$$

Equations (6)-(8) become

$$
\begin{aligned}
& \int_{0}^{1} \tilde{\mathrm{p}} \xi=1, \\
& \alpha \tilde{\mathrm{m}}_{p}^{\prime}=\widetilde{\mathrm{m}}_{p}^{\prime} \widetilde{\mathrm{T}}_{\mathrm{p}}-\frac{\mathrm{c}_{\mathrm{s}}}{\mathrm{c}_{\mathrm{p}}} \widetilde{\mathrm{m}}_{\mathrm{s}} \widetilde{\mathrm{T}}_{s}^{\prime}+\widetilde{\mathrm{m}}_{\mathrm{p}} \widetilde{\mathrm{T}}_{\mathrm{p}}^{\prime}, \\
& \widetilde{\mathrm{p}}\left[\left(\widetilde{\mathrm{T}}_{\mathrm{p}}^{4}-\widetilde{\mathrm{T}}_{\mathrm{s}}^{4}\right)+4 \lambda\left(\widetilde{\mathrm{T}}_{\mathrm{p}}^{3}-\widetilde{\mathrm{T}}_{\mathrm{s}}^{3}\right)+6 \lambda^{2}\left(\widetilde{\mathrm{T}}_{\mathrm{p}}^{2}-\widetilde{\mathrm{T}}_{\mathrm{s}}^{2}\right)+4 \lambda^{3}\left(\widetilde{\mathrm{T}}_{\mathrm{p}}\right.\right. \\
& \left.\left.\quad-\widetilde{\mathrm{T}}_{\mathrm{s}}\right)\right]=-\widetilde{\mathrm{m}}_{\mathrm{s}} \frac{\mathrm{d} \widetilde{\mathrm{T}}_{\mathrm{s}}}{\mathrm{d} \xi},
\end{aligned}
$$

where

$$
\widetilde{\mathrm{m}}_{\mathrm{s}}=\frac{\mathrm{m}_{\mathrm{s}}}{\mathrm{m}_{\text {scale }}}, \quad \widetilde{\mathrm{m}}_{\mathrm{p}}=\frac{\mathrm{m}_{\mathrm{p}}}{\mathrm{m}_{\text {scale }}}, \quad \alpha=\frac{\mathrm{a}}{\mathrm{c}_{\mathrm{p}} \Delta \mathrm{T}}, \quad \lambda=\frac{\mathrm{T}_{0}}{\Delta \mathrm{T}} .
$$

The two boundary conditions necessary for integrating Eqs. (12) and (13) are

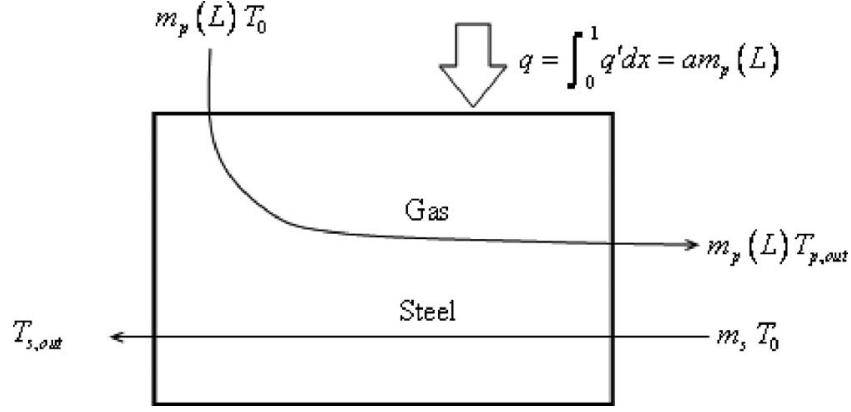

FIG. 3. The overall control volume of the furnace.

$$
\widetilde{\mathrm{T}}_{\mathrm{s}}(0)=1 \quad \text { and } \quad \widetilde{\mathrm{T}}_{\mathrm{s}}(1)=0
$$

\section{WHY THERE IS AN OPPORTUNITY TO DISTRIBUTE THE HEATING}

Consider now the control volume that contains the entire furnace with all its streams, Fig. 3. The gases come in cold $\left(\mathrm{T}_{0}\right)$ and exit hot $\left(\mathrm{T}_{\mathrm{p}, \text { out }}\right)$. The total mass flow rate $\mathrm{m}_{\mathrm{p}}$ is contributed by an unspecified number of burners distributed over the length $\mathrm{L}$. The flow rate $\mathrm{m}_{\mathrm{p}}$ is proportional to the total heating rate provided by the burners,

$$
\mathrm{q}=\int_{0}^{\mathrm{L}} \mathrm{q}^{\prime} \mathrm{dx}=\operatorname{am}_{\mathrm{p}}(\mathrm{L}) \text {. }
$$

The first law of thermodynamics requires

$$
\operatorname{am}_{\mathrm{p}}(\mathrm{L})=\mathrm{m}_{\mathrm{p}}(\mathrm{L}) \mathrm{c}_{\mathrm{p}}\left(\mathrm{T}_{\mathrm{p}, \text { out }}-\mathrm{T}_{0}\right)+\mathrm{m}_{\mathrm{s}} \mathrm{c}_{\mathrm{s}}\left(\mathrm{T}_{\mathrm{s}, \text { out }}-\mathrm{T}_{0}\right) .
$$

This is a simple equation linking two variables, the amount of fuel burned [proportional to $\mathrm{m}_{\mathrm{p}}(\mathrm{L})$ ], and the exhaust temperature $\left(\mathrm{T}_{\mathrm{p} \text {,out }}\right)$. Desirable is a lower $\mathrm{m}_{\mathrm{p}}(\mathrm{L})$, which corresponds to a lower $\mathrm{T}_{\mathrm{p} \text {,out }}$. How this is achieved depends on the internal design of the furnace.

\section{SPATIAL DISTRIBUTION OF HEATING}

Assume that the burners are distributed such that

$$
\tilde{\mathrm{m}}_{\mathrm{p}}=\mu\left[\varepsilon+(1-\varepsilon) \xi^{\mathrm{n}}\right],
$$

where the number $\mu=\widetilde{m}_{\mathrm{p}}(1)$ represents the total rate of fuel consumption, $\varepsilon$ is a small number (e.g., $\varepsilon=0.1$, not to be confused with the emissivities used in $\mathrm{F}^{\prime}$ ) accounting for the relative size of the first burner, and $\mathrm{n}$ accounts for the manner in which the burners are distributed. For example, $n=1$ represents a uniform distribution of burners along $\mathrm{L}$. To focus on the effect of distributed burners (n), we start with the assumption that $\mathrm{p}$ is constant, i.e., the furnace has a onedimensional design,

$$
\widetilde{\mathrm{p}}=1 \text {. }
$$

The dimensionless factors appearing in Eqs. (12) and (13) have the values $\alpha=\mathrm{a} / \mathrm{c}_{\mathrm{p}} \Delta \mathrm{T}=1.8$ (corresponding to $\mathrm{a}=2.75$ $\times 10^{6} \mathrm{~J} / \mathrm{kg}, \mathrm{c}_{\mathrm{p}}=1270 \mathrm{~J} / \mathrm{kg} \mathrm{K}$, and $\left.\Delta \mathrm{T}=1200 \mathrm{~K}\right), \mathrm{F}^{\prime}=1, \lambda$ $=0.25$, and $c_{\mathrm{s}} / \mathrm{c}_{\mathrm{p}}=0.46$. The steel mass flow rate $\widetilde{\mathrm{m}}_{\mathrm{s}}$ was given several values in the range $0.1-1$. 


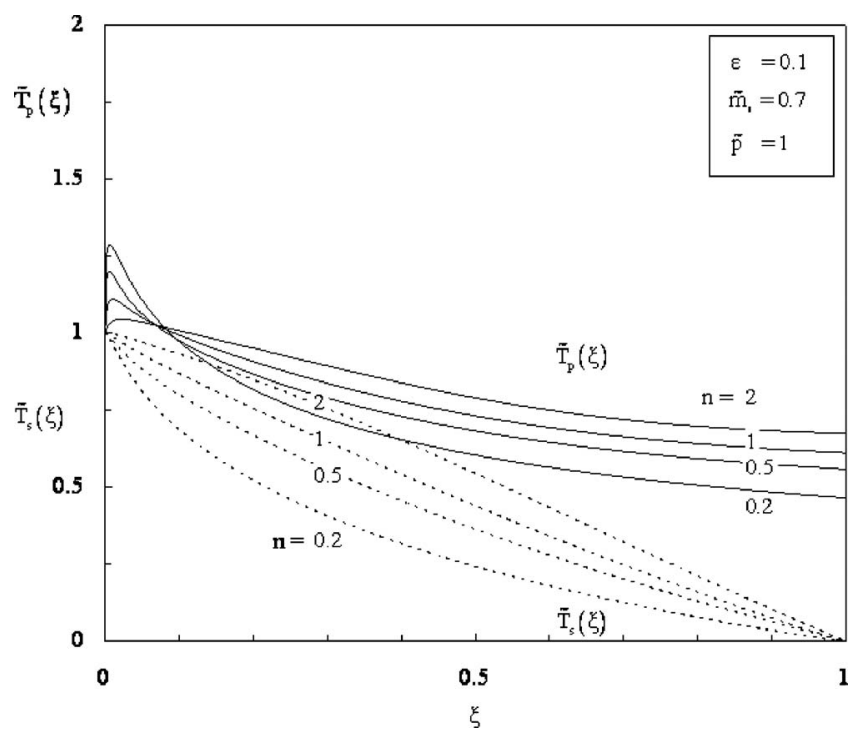

FIG. 4. The temperature distributions along the steel, $\widetilde{\mathrm{T}}_{\mathrm{s}}(\xi)$, and the products of combustion, $\widetilde{T}_{\mathrm{p}}(\xi)$, showing the distributed heating effect $(\mathrm{n})$.

To start, we set $\mathrm{n}=1$ and $\mu=0.309$. We integrated Eqs. (12) and (13) and found the temperature distributions $\widetilde{\mathrm{T}}_{\mathrm{s}}(\xi)$ and $\widetilde{\mathrm{T}}_{\mathrm{p}}(\xi)$ plotted in Fig. 4 . We then lowered $\mu$ and repeated the calculation. We found that as the total fuel consumption $(\mu)$ decreases, $\widetilde{\mathrm{T}}_{\mathrm{s}}$ rises to the point that it threatens the design condition that the highest $\widetilde{\mathrm{T}}_{\mathrm{s}}$ value must occur at the exit from the furnace. In this way, we determined the lowest fuel consumption $\left(\mu_{\min }\right)$ as the design where

$$
\frac{\mathrm{d} \widetilde{\mathrm{T}}_{\mathrm{s}}}{\mathrm{d} \xi}=0 \quad \text { at } \quad \xi=0
$$

This first set of simulations revealed the minimal fuel consumption $\mu_{\min }$ that corresponds to the specified $\widetilde{\mathrm{m}}_{\mathrm{s}}$ and $\mathrm{n}$. We repeated these simulations for many pairs $\left(\widetilde{\mathrm{m}}_{\mathrm{s}}\right.$ and $\left.\mathrm{n}\right)$, and found the surface $\mu_{\min }\left(\widetilde{\mathrm{m}}_{\mathrm{s}}\right.$ and $\left.\mathrm{n}\right)$ represented in Fig. 5. Important here is the discovery that for the specified stream of steel $\left(\widetilde{\mathrm{m}}_{\mathrm{s}}\right)$ there exists a spatial distribution of burners $\left(\mathrm{n}_{\mathrm{opt}}\right)$ such that the minimal fuel consumption $\left(\mu_{\min }\right)$ is the smallest that it can be, namely, $\mu_{\text {min,min }}$.

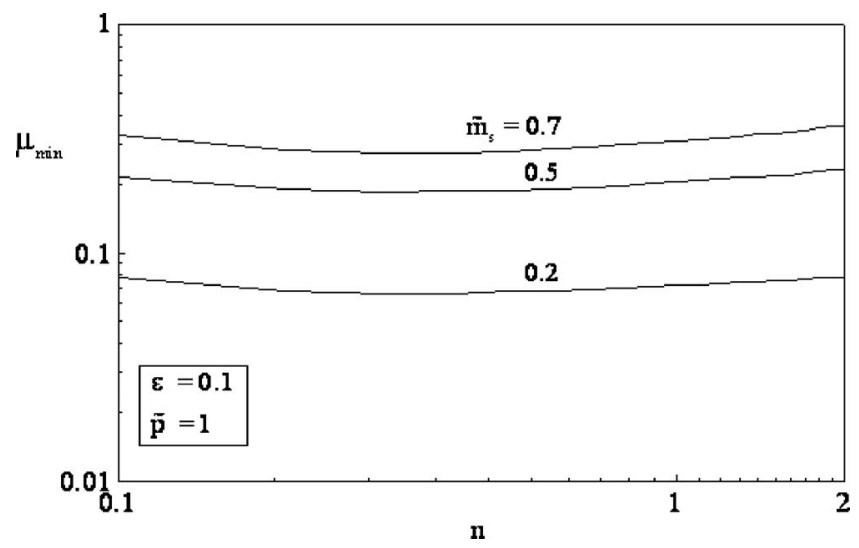

FIG. 5. The total minimal fuel consumption $\mu_{\min }$ that corresponds to the specified $\widetilde{\mathrm{m}}_{\mathrm{s}}$, showing that $\mu_{\min }$ can be minimized with respect to $\mathrm{n}$.
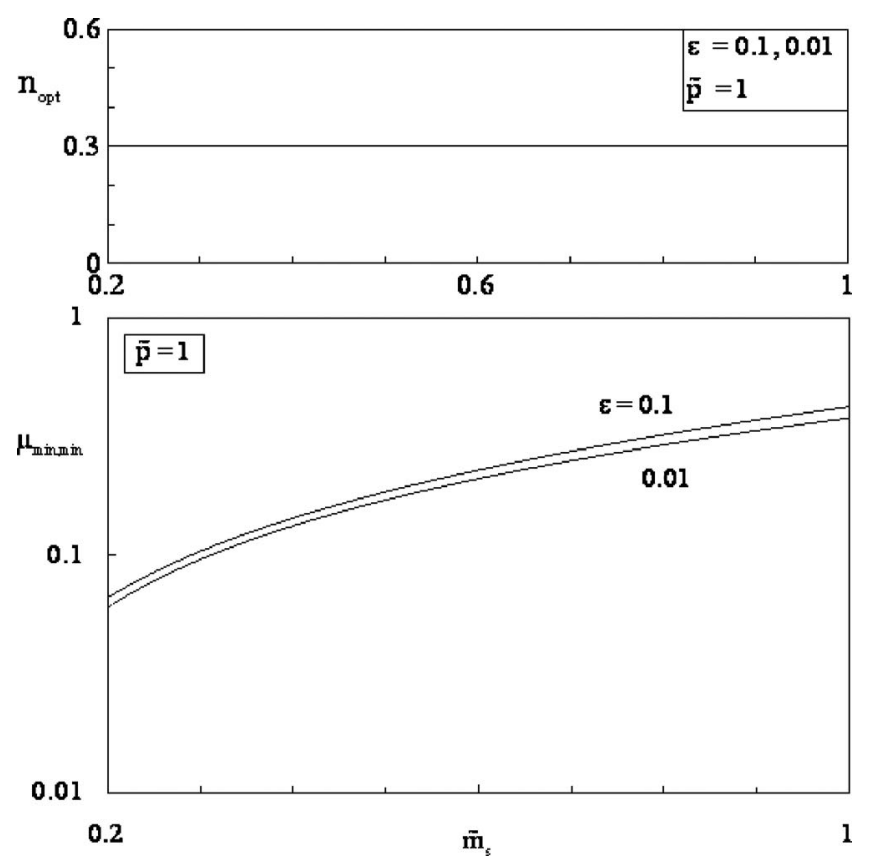

FIG. 6. The optimal distribution of burners $\left(\mathrm{n}_{\mathrm{opt}}\right)$, and the smallest fuel consumption $\left(\mu_{\min , \min }\right)$, as functions of flow rate.

The optimally distributed design is summarized as the functions $\mathrm{n}_{\text {opt }}\left(\widetilde{\mathrm{m}}_{\mathrm{s}}\right)$ and $\mu_{\text {min,min }}\left(\widetilde{\mathrm{m}}_{\mathrm{s}}\right)$ shown in Figs. 6 and 7. Noteworthy is that $n_{\text {opt }}$ is equal to approximately 0.3 over the entire $\widetilde{\mathrm{m}}_{\mathrm{s}}$ range $0.1-1$. This means that the best way to distribute the burners is as $d \widetilde{m}_{\mathrm{p}} / \mathrm{d} \xi \sim \xi^{-0.7}$, which recommends the use of considerably more burners near the exit $(\xi=0)$ than near the entrance $(\xi=1)$.

The relative merit of using the optimal (nonuniform) distribution of burners $\left(\mathrm{n}_{\mathrm{opt}}=0.3\right)$ is presented in Fig. 7, where the reference design is the one where the burners are distributed uniformly $(\mathrm{n}=1)$. The ratio $\mu_{\min }(\mathrm{n}=0.3) / \mu_{\min }(\mathrm{n}=1)$ has values of order of 0.9 , indicating a $10 \%$ reduction in the total rate of fuel consumption when the heating is distributed nonuniformly.

\section{TAPERED FLOOR AREA}

In the preceding examples the furnace was modeled as one dimensional, with an $\mathrm{x}$-independent surface of contact

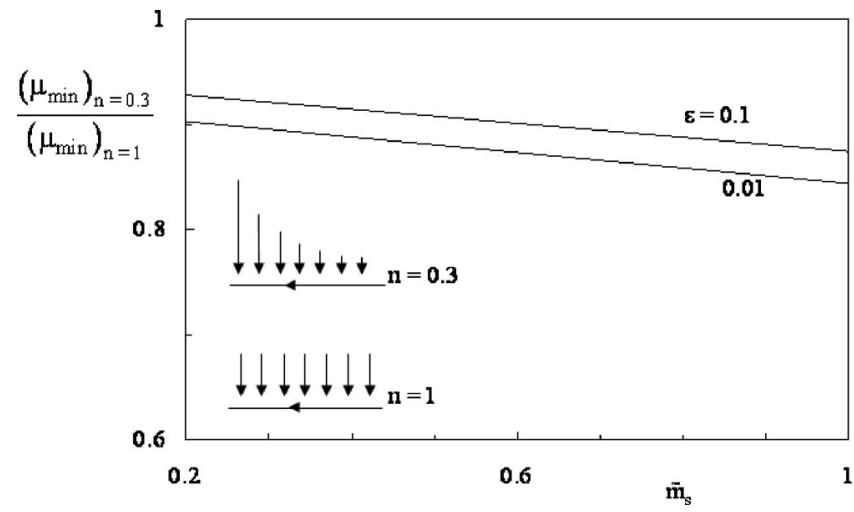

FIG. 7. The merit of using the optimal nonuniform distribution of heaters $(\mathrm{n}=0.2)$ relative to using uniformly distributed heaters $(\mathrm{n}=1)$. 


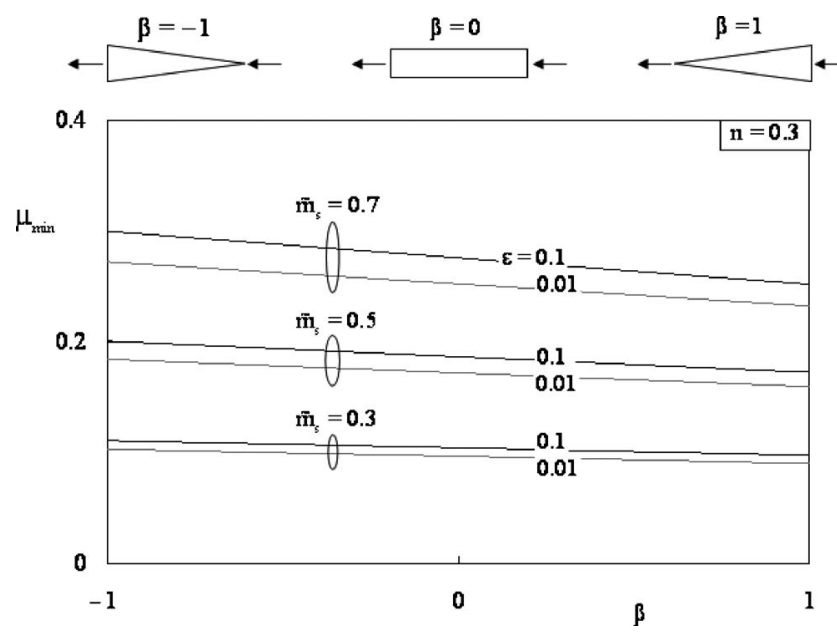

FIG. 8. The effect of the tapering of the floor area and the computational constant $\varepsilon$ on the minimal fuel consumption $\mu_{\min }$.

between steel and hot gases, see $\tilde{p}=1$ in Eq. (19). Consider now the more general case where the contact surface is distributed in a certain way longitudinally, $\widetilde{\mathrm{p}}(\xi)$, while obeying the total area constraint [Eq. (11)]. To illustrate, assume that $\tilde{\mathrm{p}}$ varies linearly with $\xi$,

$$
\widetilde{\mathrm{p}}=1+\beta(2 \xi-1)
$$

where $\beta$ accounts for taper of the area $\mathrm{A}$ in the $\mathrm{x}$ direction. Note that Eq. (21) obeys the integral constraint. Furthermore, because $\tilde{\mathrm{p}}>0$, the values that $\beta$ can have are in the range $(-1,1)$.

We explored numerically the effect of $\beta$ on the minimal fuel requirement. To isolate the effect of $\beta$, we first fixed $\varepsilon$ $=0.01$ and $\widetilde{\mathrm{m}}_{\mathrm{s}}=0.5$. Although the distribution of hot gases $(\mathrm{n})$ is not fixed (it can be optimized, see Fig. 5, namely, $\mathrm{n}_{\mathrm{opt}}$ $=0.3$ when the furnace is not tapered, $\beta=0$ ), we fix $n=0.3$ as we begin the search for the best taper. The effect of $\beta$ on $\mu_{\min }$ is displayed in Fig. 8. The total fuel requirement $\left(\mu_{\min }\right)$ decreases monotonically as the angle of the furnace floor area increases. This effect becomes more noticeable as $\tilde{\mathrm{m}}_{\mathrm{s}}$ increases.

The conclusion is that tapering the plan view of the heating area yields reductions in the overall fuel requirement. The best taper is $\beta=1$, which represents a triangular floor on which the cold steel enters by crossing the base. For example, when $\widetilde{\mathrm{m}}_{\mathrm{s}}=0.7$ the reduction in fuel use from the rectangular floor design $(\beta=0)$ to the triangular floor $(\beta=1)$ is $8 \%$. This conclusion is further supported by Fig. 8 , which shows that if we use a different value of $\varepsilon$ in our numerical simulations the variation in $\mu_{\min }$ versus $\beta$ is the same as for $\varepsilon=0.01$.

So far, we have assumed that the longitudinal distribution of heating is represented by $n=0.3$, which is the optimal value for the floor design without taper $(\beta=0)$. In Fig. 9 we relaxed this assumption while considering the nearly triangular floor design with $\beta=1$. Figure 9 shows how the fuel requirement $\mu_{\text {min }}$ varies with the distribution of the fuel, $\mathrm{n}$. When $\varepsilon=0.1$, the minimum of $\mu_{\min }$ falls in the range 0.1 $<\mathrm{n}<0.3$, and shows a tendency toward $\mathrm{n}$ values lower than

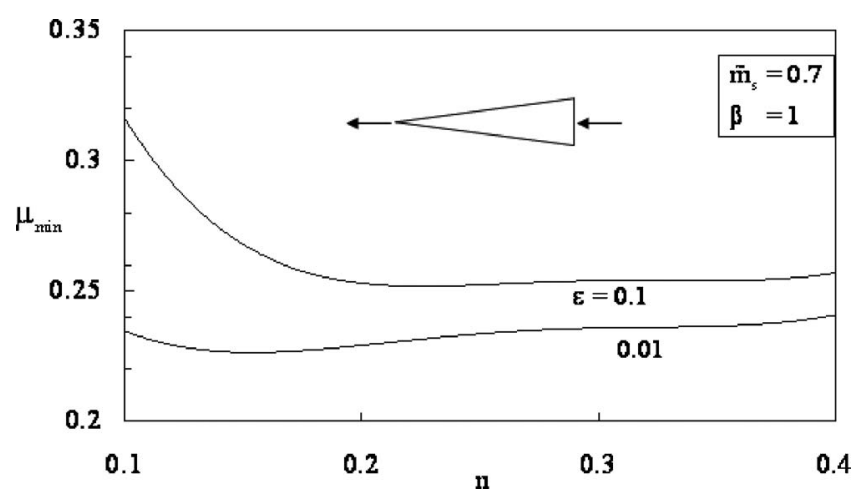

FIG. 9. The effect of the longitudinal distribution of heating (n) on the minimal fuel requirement when the floor area is tapered optimally.

0.3 . When $\varepsilon=0.01$, the minimum of $\mu_{\min }$ occurs at $\mathrm{n}=0.14$, which is not too far from the value $n=0.3$ assumed in the simulations that led to Fig. 8.

It is worth noting that when the floor is tapered the wrong way $(\beta=-1)$, with the narrow end serving as entrance for the stream of steel (Fig. 10), the optimal distribution of heating is represented by $n \cong 0.23$, which is sensibly smaller than 0.3. This conclusion is a little sensitive to the small value assigned to $\varepsilon$.

\section{DENDRITIC FLOW ON THE FURNACE FLOOR}

The design implication of the superiority of the tapered furnace $(\beta=1$, Fig. 8) is that the flow of steel must have a density that increases in the flow direction. The density of the flow of steel is represented by the number of steel slabs per unit area. This stream rides on one or more conveyors. The steel slabs are indicated as vertical bars, which are perpendicular to the flow direction. If the floor is not tapered $(\beta=0)$, then the density of steel slabs on the conveyor is uniform (Fig. 11, top). If the floor area is triangular (Fig. 11, middle and bottom), the density increases to the left, as more conveyors are positioned in parallel where the floor is wide. Following the flow of steel, we see that every pair of lowdensity conveyors feeds one conveyor on which the density of slabs is twice as large as on the tributaries.

Conveyors that happen to be aligned with the centerline (e.g., Fig. 11, middle) are superpositions of two tributaries and, consequently, their steel-slab density is twice as large as

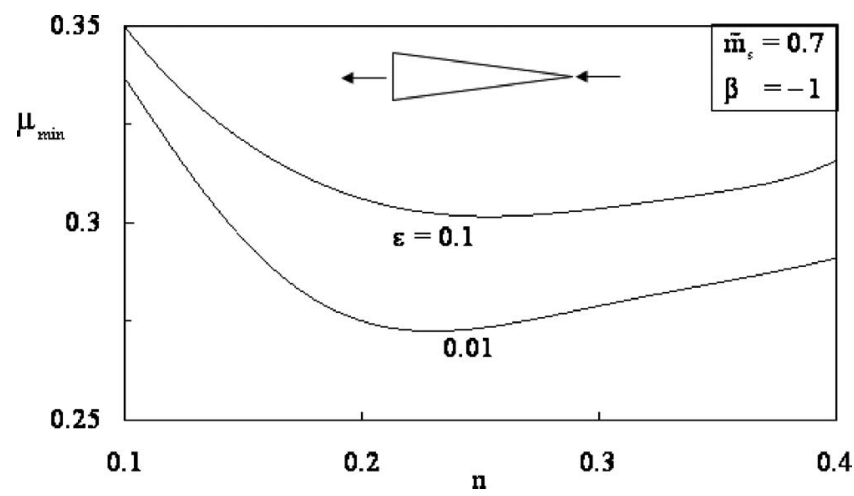

FIG. 10. The effect of the longitudinal distribution of heating (n) on the minimal fuel requirement when the floor area is tapered the wrong way. 
$\hookleftarrow \quad[|||||||||||||||||||||||||||||||||||||||||||||||||||||||||||||||||||||||||||||||||||||||||||||||||||||||||||| \mid \downarrow$
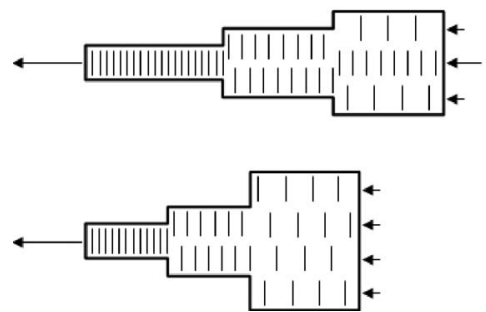

FIG. 11. The distribution of the flow of steel on the furnace floor: uniform density, on a floor with uniform width (top) and increasing density, on triangular floors (middle and bottom). The total flow rate $\mathrm{m}_{\mathrm{s}}$ and the floor area are the same in each drawing.

in a single tributary. The steel stream from one of the centerline conveyors is discharged in alternating fashion to the next two "mother" channels that continue the flow of steel to the left. The tree-shaped paths of the flow of steel on the triangular floor are shown in Fig. 12 (middle and bottom).

The distribution of heaters per unit area depends on the shape of the floor. Assume that the heater distribution versus $\mathrm{x}$ is represented by the exponent $\mathrm{n}=0.3$, which we found to be near-optimal for both floor designs, constant-width and triangular. This means that in both designs the density of heaters per unit length in the $\mathrm{x}$ direction (Fig. 1) must decrease as $\mathrm{x}^{-0.7}$, as shown in Sec. IV.

The density of heaters per unit area varies as $x^{-0.7} / p(x)$. In the constant-p design, the area density of heaters decreases as $x^{-0.7}$ toward the steel entrance. This is shown in the upper drawing of Fig. 13. In the triangular designs, the area density decreases more sharply, as $x^{-1.7}$. Two distributions of heaters on triangular areas are shown in Fig. 13 (middle and bottom). The three drawings of Fig. 13 have the same area, which is the same as the area shown in Figs. 11 and 12.

\section{CONCLUSIONS}

This paper suggested analytically novel configurations for heating a stream by radiation from a large number of heaters. The distributions of cross-sectional area and heaters are free to vary in the search for the overall minimal fuel consumption.

The best way to distribute the heaters recommends the use of considerably more heaters near the exit than near the entrance. The relative merit of using the optimal (nonuni-
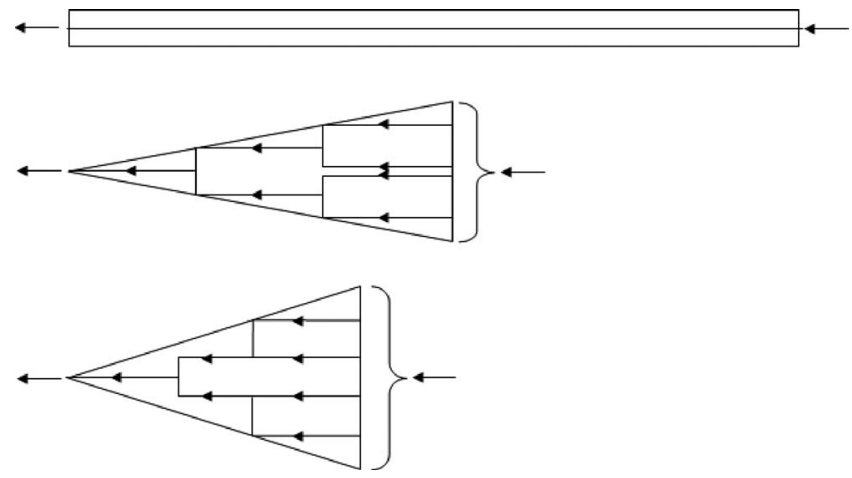

FIG. 12. The direction of the steel streams and their tributaries in Fig. 11.

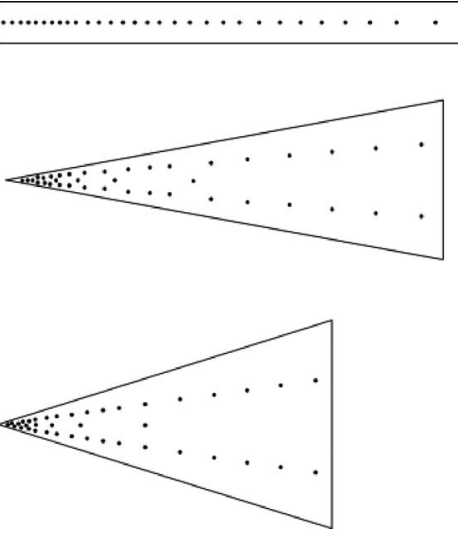

FIG. 13. The distribution of heaters on the area occupied by the three designs of Fig. 11.

form) distribution of heaters indicated a $10 \%$ reduction in the total rate of fuel consumption when the heating is distributed nonuniformly.

Tapering the plan view of the heating area yields reductions in the overall fuel requirement. The best taper is $\beta=1$, which represents a triangular floor on which the cold steel enters by crossing the base. The distribution of heaters per unit area depends on the shape of the floor. The density of heaters per unit area varies as $x^{-0.7} / p(x)$. In the constant-p design, the area density of heaters decreases as $x^{-0.7}$ toward the steel entrance. In the triangular designs, the area density decreases more sharply, as $x^{-1.7}$.

The analysis presented in this paper is important in a fundamental sense, because it unveils a new direction for the design of industrial furnaces with minimal fuel consumption. This could be pursued in more rigorous thermodynamics terms based on a more complete model of the heating installation. In Fig. 14, for example, we account for the fact that a stream of liquid water $\left(\mathrm{m}_{\mathrm{w}}\right)$ must be pumped through the solid mechanism that serves as conveyor for the stream of solid (e.g., steel laminators). The water stream enters at ambient conditions, and exits at a temperature that is essentially fixed because it cannot exceed the boiling temperature. The enthalpy rate removed by the water stream from the enclosure, $\mathrm{m}_{\mathrm{w}}\left(\mathrm{h}_{\text {out }}-\mathrm{h}_{\text {in }}\right)$, is expected to be a minor effect in the energy balance, however, it is fixed because it is set by the heat transfer rate from the hot gases to the water stream. This heat transfer rate is fixed by the size of the enclosure (or the

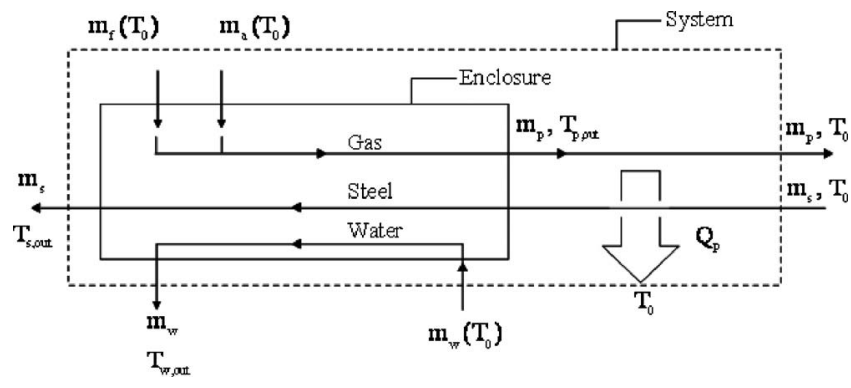

FIG. 14. Heating installation with water cooling for its mechanical support structure and heat rejection during the flow of the products of combustion into the ambient. 
area of heat transfer contact) and the order of magnitude of the gas temperature. The result is that the water flow rate is also fixed.

The key observation in Fig. 14 is that after discharge from the enclosure the products of combustion are in contact with the ambient to which they lose heat at the rate of $\mathrm{Q}_{\mathrm{P}}$, before reaching the ambient temperature $\mathrm{T}_{0}$. The complete thermodynamic system of interest is the system defined by the dashed line. For this system, the first law of thermodynamics requires

$$
\begin{aligned}
& \left(\mathrm{m}_{\mathrm{f}} \mathrm{h}_{\mathrm{f}, 0}+\mathrm{m}_{\mathrm{a}} \mathrm{h}_{\mathrm{a}, 0}+\mathrm{m}_{\mathrm{s}} \mathrm{h}_{\mathrm{s}, 0}+\mathrm{m}_{\mathrm{w}} \mathrm{h}_{\mathrm{w}, 0}\right)-\left(\mathrm{m}_{\mathrm{p}} \mathrm{h}_{\mathrm{p}, 0}+\mathrm{m}_{\mathrm{s}} \mathrm{h}_{\mathrm{s}, \text { out }}\right. \\
& \left.\quad+\mathrm{m}_{\mathrm{w}} \mathrm{h}_{\mathrm{w}, \text { out }}\right)=\mathrm{Q}_{\mathrm{p}} .
\end{aligned}
$$

The second law of thermodynamics requires $S_{\text {gen }}>0$, where

$$
\begin{aligned}
\mathrm{S}_{\mathrm{gen}}= & \frac{\mathrm{Q}_{\mathrm{p}}}{\mathrm{T}_{0}}+\left(\mathrm{m}_{\mathrm{p}} \mathrm{s}_{\mathrm{p}, 0}+\mathrm{m}_{\mathrm{s}} \mathrm{s}_{\mathrm{s}, \text { out }}+\mathrm{m}_{\mathrm{w}} \mathrm{s}_{\mathrm{w}, \text { out }}\right)-\left(\mathrm{m}_{\mathrm{f}} \mathrm{s}_{\mathrm{f}, 0}\right. \\
& \left.+\mathrm{m}_{\mathrm{a}} \mathrm{s}_{\mathrm{a}, 0}+\mathrm{m}_{\mathrm{s}} \mathrm{s}_{\mathrm{s}, 0}+\mathrm{m}_{\mathrm{w}} \mathrm{s}_{\mathrm{w}, 0}\right) .
\end{aligned}
$$

By eliminating $Q_{P}$ between Eqs. (22) and (23) we obtain the rate of entropy generation $\left(\mathrm{S}_{\mathrm{gen}}\right)$, or the rate of exergy destruction $\left(\mathrm{T}_{0} \mathrm{~S}_{\mathrm{gen}}\right)$, namely,

$$
\begin{aligned}
\mathrm{T}_{0} \mathrm{~S}_{\mathrm{gen}}= & \mathrm{m}_{\mathrm{f}}\left(\mathrm{h}-\mathrm{T}_{0} \mathrm{~s}\right)_{\mathrm{f}, 0}+\mathrm{m}_{\mathrm{a}}\left(\mathrm{h}-\mathrm{T}_{0} \mathrm{~s}\right)_{\mathrm{a}, 0}-\mathrm{m}_{\mathrm{p}}\left(\mathrm{h}-\mathrm{T}_{0} \mathrm{~s}\right)_{\mathrm{p}, 0} \\
& +\mathrm{m}_{\mathrm{s}}\left(\mathrm{h}-\mathrm{T}_{0} \mathrm{~s}\right)_{\mathrm{s}, 0}-\mathrm{m}_{\mathrm{s}}\left(\mathrm{h}-\mathrm{T}_{0} \mathrm{~s}\right)_{\mathrm{s}, \text { out }}+\mathrm{m}_{\mathrm{w}}(\mathrm{h} \\
& \left.-\mathrm{T}_{0} \mathrm{~s}\right)_{\mathrm{w}, 0}-\mathrm{m}_{\mathrm{w}}\left(\mathrm{h}-\mathrm{T}_{0} \mathrm{~s}\right)_{\mathrm{w}, \text { out }}
\end{aligned}
$$

In this summation, all the terms are fixed except the first two, which vary in proportion with the total amount of fuel $\left(\mathrm{m}_{\mathrm{f}}\right)$, because stoichiometry requires a certain proportionality between $\mathrm{m}_{\mathrm{a}}$ and $\mathrm{m}_{\mathrm{f}}$.

In conclusion, to minimize the rate of exergy destruction in the heating installation is equivalent to what we presented in this paper, namely, the minimization of the total rate of fuel consumption. For the heating process, this approach is the same as performing thermodynamic optimization, entropy generation minimization, or exergy analysis and the minimization of exergy destruction.

\section{ACKNOWLEDGMENTS}

This research was supported by RIST (Research Institute of Industrial Science \& Technology), Pohang, South Korea.

${ }^{1}$ A. Bejan and S. Lorente, Design with Constructal Theory (Wiley, New Jersey, 2008)

${ }^{2}$ A. Bejan and S. Lorente, Philos. Trans. R. Soc. London, Ser. B 365, 1335 (2010).

${ }^{3}$ N. Chakraborti, K. Deb, and A. Jha, Steel Res. 71, 396 (2000).

${ }^{4}$ F. Hollander and S. P. A. Zuurbier, Iron Steel Eng. 59, 44 (1982).

${ }^{5}$ B. Leden, Scand. J. Metall. 15, 16 (1986).

${ }^{6}$ Y. I. Kim, K. C. Moon, B. S. Kang, C. H. Han, and K. S. Chang, Control Eng. Pract. 6, 1009 (1998)

${ }^{7}$ A. Dunoyer, K. J. Burnham, and T. S. McAlpine, IEE Proc.: Control Theory Appl. 144, 25 (1997).

${ }^{8}$ H. S. Ko, J. S. Kim, T. W. Yoon, M. Lim, D. R. Yang, and I. S. Jun, American Control Conference, Chicago, USA, June 2000, Vol. 4, pp. 2725-2729

${ }^{9}$ Y. Misaka, R. Takahashi, A. Shinjo, Y. Nariai, and M. Kooriki, Iron Steel Eng. 59, 51 (1982).

${ }^{10}$ Y.-Y. Yang and Y.-Z. Lu, Comput Ind. 10, 11 (1988).

${ }^{11}$ L. M. Pedersen and B. Wittenmark, American Control Conference, Philadelphia, PA, U.S.A., June 1988, Vol. 6, pp. 3811-3815.

${ }^{12}$ B. Zhang, Z. Chen, L. Xu, J. Wang, J. Zhang, and H. Shao, American Control Conference, 2002, Vol. 5, pp. 3823-3828.

${ }^{13}$ H. Ezure, Y. Seki, N. Yamaguchi, and H. Shinonaga, Electr. Eng. Jpn. 120, 42 (1998).

${ }^{14}$ Z. Li, P. V. Barr, and J. K. Brimacombe, Can. Metall. Q. 27, 187 (1988).

${ }^{15}$ J. G. Kim, K. Y. Huh, and I. T. Kim, Numer. Heat Transfer 38, 589 (2000).

${ }^{16}$ D. Lindholm, Numer. Heat Transfer 35, 155 (1999).

${ }^{17}$ M. Y. Kim, Int. J. Heat Mass Transfer 50, 3740 (2007).

${ }^{18}$ A. Jakliča, F. Vodea, and T. Kolenkob, Appl. Therm. Eng. 27, 1105 (2007).

${ }^{19}$ S. H. Han, S. W. Baek, S. H. Kang, and C. Y. Kim, Int. J. Heat Mass Transfer 50, 2019 (2007).

${ }^{20}$ C. T. Hsieh, M. J. Huang, S. T. Lee, and C. H. Wang, Numer. Heat Transfer 53, 966 (2008)

${ }^{21}$ T. Kolenko, B. Glogovac, and T. Jakli, Commun. Numer. Methods Eng. 15, 349 (1999).

${ }^{22}$ A. Bejan, Advanced Engineering Thermodynamics, 3rd ed. (Wiley, New York, 2006). 